\title{
COMIDA COMO CULTURA? \\ NOTAS SOBRE A PATRIMONIALIZAÇÃO ALIMENTAR E SUA RELAÇÃO COM O TURISMO GASTRONÔMICO
}

\author{
Maria Henriqueta Sperandio Garcia Gimenes-Minasse \\ Universidade Federal de São Carlos - Campus Sorocaba. \\ Email: mariegimenes@gmail.com
}

\section{RESUMO}

A alimentação é uma prática cultural cotidiana, com múltiplos significados e valores. No âmbito do turismo, a alimentação é um serviço fundamental para a permanência do turista e também a possibilidade de uma experiência cultural. Tal perspectiva se insere em um contexto mais amplo, no qual movimentos associados à globalização tendem a impor o perigo da homogeneização e da padronização alimentar. Contudo, observa-se que tal ameaça também dá origem a resistências e à valorização das práticas tradicionais. Nesta perspectiva, este artigo tem como objetivo discutir a patrimonialização alimentar, pensando-a em relação ao turismo gastronômico. Para tanto, foi realizada uma revisão bibliográfica que abrangeu autores como Contreras e Gracia (2011), Csergo (1988), Fischler (1979), Hjalager e Richards (2002), Poulain (2004) e Schlüter (2006). Como resultados, apresenta-se a concatenação de contribuições dos autores citados em uma reflexão sobre a inserção do patrimônio gastronômico no âmbito da atividade turística.

Palavras-chave: Alimentação. Patrimônio. Turismo gastronômico. 


\title{
FOOD AS CULTURE? \\ NOTES ON FOOD PATRIMONIALIZATION AND ITS RELATION TO THE GASTRONOMIC TOURISM
}

\author{
Maria Henriqueta Sperandio Garcia Gimenes-Minasse \\ Universidade Federal de São Carlos - Campus Sorocaba. \\ Email: mariegimenes@gmail.com
}

\begin{abstract}
Food is an everyday cultural practice, with multiple meanings and values. In the context of tourism, food is a key service for tourists and gives them the possibility of a cultural experience. This perspective is part of a larger context in which movements associated with globalization tend to impose the danger of homogenization and standardization of food. However, it is observed that such a threat also gives rise to resistance and enhancement of traditional practices. In this perspective, this article aims to discuss food patrimonialization, addressing it in relation to gastronomic tourism. Therefore, a literature review covering authors such as Contreras and Gracia (2011), Csergo (1988), Fischler (1979), Hjalager and Richards (2002), Poulain (2004) and Schlüter (2006) was performed. As a result, this article highlights a concatenation of contributions of the authors cited regarding the insertion of the gastronomic heritage in the context of tourism.
\end{abstract}

Key words: Food, heritage, Gastronomic tourism. 


\section{INTRODUÇÃO}

Muito já foi escrito sobre os efeitos socioeconômicos e culturais do advento da sociedade urbano industrial e o fortalecimento do processo de globalização. Para Ortiz (1996), esses movimentos terminam por alterar o tecido social, na medida em que interferem não apenas em como os bens e a informação circulam, mas também na maneira com que os laços entre indivíduos são estabelecidos:

Os laços de solidariedade se rompem. O anonimato das grandes cidades e do capitalismo corporativo pulveriza as relações sociais existentes, deixando os indivíduos "soltos" na malha social. A sociedade deve portanto inventar novas instâncias para a integração das pessoas (Ortiz, 1996, p.119).

Considerando que a alimentação é uma prática cultural que responde a um contexto mais amplo, é fácil perceber exemplos de transformação dos hábitos alimentares em conformidade aos novos ritmos e características da sociedade contemporânea. A distância entre a casa e o trabalho, a inserção da mulher no mercado de trabalho, os horários destinados às refeições cada vez mais reduzidos são alguns dos elementos que alteraram a estrutura alimentar contemporânea. Para a falta de tempo, come-se em qualquer lugar (inclusive nos carros), de preferência em refeitórios ou restaurantes próximos ao local de trabalho. Como Garine (1987) defende, atualmente é possível comer qualquer alimento, em qualquer momento, em qualquer lugar, em qualquer quantidade, desde que se possa pagar por isso.

Como consequência, os antigos rituais de comensalidade-exercício fundamental de sociabilidade e hospitalidade - também são afetados, fazendo com que muitas vezes seu exercício cotidiano seja desmantelado. Atualmente, é comum encontrar famílias que, em face da agenda de cada um de seus integrantes (mesmo as crianças),fazem suas refeições de forma isolada, ou melhor, acompanhadas muitas vezes por um aparelho de televisão ou microcomputador. $\mathrm{O}$ "estar à mesa com a família ou amigos" fica muitas vezes restrito aos finais de semana, onde o ponto de encontro se torna cada vez mais um restaurante, e não a residência de algum dos envolvidos.

Por si só, a expansão dos restaurantes, bares e similares merece nota, não apenas do ponto de vista do volume de estabelecimentos, mas também por conta dos inúmeros papéis absorvidos por estes empreendimentos: eles se consolidaram como espaços de lazer, tidos muitas vezes como uma expansão da própria residência. Estes lugares são então frequentados pela praticidade de se comer fora, pela possibilidade de se degustar iguarias que não se sabe - ou não se deseja - preparar, para passar horas agradáveis com familiares e amigos, para conhecer pessoas, para demarcar status social ou pertencimento 
a um determinado grupo, dentre tantas outras finalidades.

Outra desinência importante desse processo consiste na própria maneira de se produzir e se preparar os alimentos. As alterações nas formas de preparação são mais evidentes, pois literalmente "adentram" nossas cozinhas: comidas congeladas, prépreparadas e desidratadas também contribuem para a rotina de quem tem pressa, e, aliados a equipamentos diversos (freezers, microondas, fornos elétricos) transformam qualquer um em "cozinheiro", mesmo que não se tenha habilidade alguma. Menos visíveis, mas igualmente importantes, são as transformações no âmbito da produção dos alimentos/ ingredientes em si.

Para Contreras e Gracia (2011), nunca, no âmbito da história, um indivíduo teve acesso a uma tal diversidade alimentar como agora no Ocidente. Mesmo que a fome ainda assombre diversas regiões do mundo, a superabundância alimentar (em termos de quantidade e também diversidade) também é uma realidade contemporânea. E este fenômeno apenas se tornou possível por conta do processo de industrialização alimentar, que ganhou impulso na Europa na década de 1960, proveniente dos Estados Unidos, onde já estava consolidado desde o final do século XIX. Para Contreras e Gracia (2011, p.426):

Em términos generales, puede afirmarse que, desde la década de 1950, sobre todo, la alimentación ordinária se ha homogeneizado progresivamente como consecuencia de haber pasado, em poco tiempo, de unos ecosistemas muy diversificados a otros hiperespecializados e integrados em vastos sistemas de producción agroalimentaria a escala internacional ${ }^{1}$.

Para estes autores, atualmente o mercado da alimentação não raciocina mais no âmbito nacional, já que a indústria alimentar é dominada por empresas transnacionais. Como resultado, tem-se que "o alimento moderno está deslocado, ou seja, desconectado de seu enraizamento geográfico e das dificuldades climáticas que lhe eram tradicionalmente associadas" (Contreras; Gracia, 2011, p.29).

O processo de padronização alimentar se deu, em muito, em virtude das regulamentações sobre a higiene e as políticas de qualidade adotadas pelo setor industrial, em virtude dos parâmetros necessários para a produção e comercialização desses alimentos em larga escala.). Contreras e Gracia (2011), assim como Fischler (1979) observam que os alimentos se tornam homogeneizados por conta dos padrões de seleção (que separa os mais resistentes dos menos resistentes, por exemplo) e do uso de aditivos (como corantes, colorantes e aromatizantes) que visam atender os padrões de qualidade,

1Em termos gerais, pode-se afirmar que desde a década de 1950 a alimentação cotidiana tem se homogeneizado progresivamente como consequência da transição de ecosistemas muito diversificados para outros hiperespecializados e integrados a amplos sistemas de produção agroalimentar em escala internacional. [tradução livre] 
higiene e conservação exigidos pela indústria global. Os resultados, para além do paladar, podem ser catastróficos:

De este modo ha aumentado considerablemente la producción mundial de alimentos al tiempo que han desaparecido numerosas variedades vegetales y animales que habían constituido la base de dietas de âmbito más o menos localizado ${ }^{2}$. (Gracia; Contreras, 2011, p.426).

Contreras e Gracia (2011) observam que desde o final do século XX, em qualquer país do mundo, o essencial da dieta de seu povo provém de um sistema de produção e de distribuição que de escala mundial. Se os alimentos em si estão cada vez mais padronizados, as formas de preparo não escapam a esta lógica. A criação do McDonald's na década de 1950 e a expansão alcançada por essa cadeia de restaurantes na década de 1970 (em 1974 o McDonald's inaugurou sua primeira loja na França e, em 1979, no Brasil) tornou-se um caso muito citado como exemplo da introdução de uma nova forma de produzir e realizar refeições. Com uma lógica taylorista de organização das atividades e a introdução de alterações no ritmo das refeições, o cardápio americano "hambúrguer + batata frita + refrigerante" foi incorporado em diversos países, gerando centenas de estabelecimentos semelhantes no mundo inteiro.

Coma proliferação de alimentos enlatados, desidratados, pré-cozidos, semiprontos e congelados, muitas das tarefas da cozinha doméstica foram sendo transferidas em grande medida para a indústria alimentar; e as tarefas que ainda permanecem domésticas são auxiliadas por multiprocessadores, os já citados fornos microondas e uma infinidade de gadgets culinários.

Estas novas alterações, que agem sobre ingredientes, sistemas produtivos, formas de preparo, comercialização e consumo (ou seja, afetam todo o sistema alimentar) criam um padrão chamado por Fischler (1979) de hiperhomogêneo, com a globalização e padronização da dieta em escala internacional.

Contudo, trata-se de um contexto dinâmico, no qual há espaço para resistências e ressignificações. Esta "ameaça" da homogeneização também gerou uma reação, traduzida na valorização de formas de alimentação tidas como mais tradicionais e naturais, bem como criou uma série de iniciativas buscando o reconhecimento e a salvaguarda dessas manifestações. Como observarm Contreras e Gracia (2011, p. 433) "el miedo a la estandarización está siendo utilizado por diferentes sectores (restauradores, políticos, associanes culturales) para reivindicar el mantenimiento o la restitución de las cocinas

2 Deste modo aumentou consideravelmente a produção mundial de alimentos ao mesmo tempo em que desapareceram numerosas variedades de vegetais e animais que haviam constituído a base de dietas de ámbito mais ou menos localizado.[tradução livre] 
regionales y autóctonas ${ }^{3 "}$. E o turismo, como veremos a seguir, também toma parte nesse processo.

Este artigo, que tem como objetivo geral discutir a patrimonialização alimentar, pensando-a em relação ao turismo gastronômico. Para tanto, foi realizada uma revisão bibliográfica, que buscou privilegiar os principais autores das áreas de antropologia, da história e da sociologia da alimentação na atualidade, bem como autores dedicados à temática turismo gastronômico.

\section{Turismo gastronômico}

Para pensar a relação gastronomia e turismo é imprescindível, antes de mais nada, abandonar a concepção de que se trata unicamente de garantir ao visitante a saciação de uma necessidade fisiológica. Por ser construída a partir de uma série de critérios socioculturais (que incluem crenças, valores e símbolos), os hábitos alimentares materializam uma série de conteúdos historicamente construídos que muito podem informar sobre um determinado grupo social.

Richards (2002) observa que na medida em que a competição entre destinos turísticos cresce, a cultura local se torna cada vez mais uma importante fonte de novos produtos e atividades para entreter e encantar turistas. E, para ele "gastronomy has a particularly important role to play in this, not only because food is central to the tourist experience, but also because gastronomy has become a significant source of identity formation in postmodern societies"4. (Richards, 2002, p.3).

Para Regina Schlüter (2006), sem dúvida não é apenas legado monumental arquitetônico ou artístico que constitui o foco do Turismo Cultural, já que outros aspectos tradicionais da cultura - incluindo a gastronomia, as festas e as danças - possuem significados simbólicos e estão relacionadas ao comportamento, ao pensamento e à expressão dos sentimentos de um determinado grupo. Estes elementos podem, sozinhos ou associados a outros atrativos, desempenhar um importante papel no consumo turístico. Quando os elementos gastronômicos se tornam centrais para o deslocamento do turista, tem-se o chamado Turismo Gastronômico. Sobre esse subsegmento do Turismo Cultural, Schlüter (1996, p.6) esclarece

Las motivaciones principales se encuentram em la búsqueda del placer a través de la alimentación y el viaje, pero dejando de lado lo estándar

3 O medo da padronização está sendo utilizado por diferentes setores (restaução, políticos, associações culturais) para reivindicar a manutenção ou a restituição das cozinhas regionais e autóctones.[tradução libre] 4 A Gastronomia possui um importante papel nisto, não apenas porque a comida é central para a experiencia turística, mas também porque a gastronomia se tornou uma fonte significativa de formação de identidade nas sociedades pós-modernas. [tradução livre] 
para favorecer lo genuíno. La búsqueda de las raíces culinárias y la forma de entender a la cultura de um lugar a través de su gastronomía está adquiriendo cada vez mayor importâncias.

Poulain (2004, p. 36) destaca que "nos discursos espontâneos dos consumidores, mas também com frequência no dos atores da produção de refeições ou do turismo, a terra e as cozinhas locais são colocadas como um 'universo tradicional', no sentido original do termo". A cozinha local torna-se então um reduto de refúgio, vista como uma "tradição imutável" em oposição a um contexto de frequente mudança, e um foco de "autenticidade", em oposição ao artificialismo encontrado nos meios urbanizados. A associação entre a gastronomia e os produtos "da terra" (sentido estrito do que é tradicionalmente produzido no local) fortalece a relação entre uma localidade e sua "mesa", criando uma expectativa em relação ao que seria um patrimônio gastronômico característico (Hughes, 1995).

Analisando o turismo gastronômico, Schlüter (1996, p.6) atesta que a cozinha regional está "[...] siendo cada vez más reconocida como valioso componente del patrimonio intangible de los pueblos. Si bien el plato está a la vista, su forma de preparación y el significado para cada sociedad son aquellos aspectos que no se ven pero que le dan su carácter distintivo". Poulain (2004, p. 34) defende que "o interesse contemporâneo sobre as cozinhas regionais deve ser situado na nostalgia de um "espaço social" em que o comedor vivia sem angústia, ao abrigo de uma culinária claramente identificada e identificante". Para o autor:

A supervalorização da tradição popular, da terra e dos produtos 'autênticos' opõe-se às angústias ligadas ao desenvolvimento da industrialização alimentar e aos riscos de diluição das identidades locais e nacionais na mundialização ou no interior de espaços mais amplos, como a Europa (Poulain, 2004, p. 40).

Para Richards (2002, p.5) a relação entre a gastronomia e a cultura local é determinante para o turismo: "given the strong relationship between food and identity, it is not surprising that food becomes an important place marker in tourism promotion. One of the basic reasons for this is the strong relationship between certain localities and certain types of foods"

5 As principais motivações se encontram na busca pelo prazer através da alimentação e da viagem, mas deixando de lado o padronizado para favorecer o genuíno. A busca pelas raízes culinárias e uma forma de entender a cultura por meio de sua gastronomia está adquirindo cada vez maior importancia. [tradução livre] 6 Está sendo cada vez mais reconhecida como um valioso componente do patrimônio intangível dos povos. Se o prato pode ser visto, sua forma de preparação e significado para cada sociedade são os aspectos que não podem ser vistos, mas que dão ao prato seu caráter distintivo. [tradução livre]

7 Dada à forte relação entre comida e identidade, não é supreendente que a comida se torne um importante diferencial em termos de promoção turística. E uma das razões básicas para isso é a intensa relação entre certas localidades e determinados tipos de comida. [tradução livre] 
Escrevendo sobre a relação entre o turismo e as cozinhas regionais na França, Julia Csergo (1988) vai além: ela associa a emergência das cozinhas regionais na França à repercussão dada pelos livros de receita e especialmente pela atividade turística e pelos guias turísticos. Segunda a autora, no final do século XIX:

Depois que a extensão e o aperfeiçoamento da rede ferroviária estimularam a moda da viagem de recreio, surgiram em série os guias turísticos codificando, aos poucos, novas modalidades de percepção de uma determinada região; são eles que, confinando de forma duradoura a particularidade culinária em representações estereotipadas, acabam por impô-la - relacionando-a com a noção de ponto de interesse - como parte integrante de um patrimônio, no mesmo nivel do mirante, da arquitetura ou dos personagens que, dai em diante, pontuam as paisagens e histórias locais (Csergo, 1988, p.187).

Para Csergo (1988), esta apropriação das especialidades gastronômicas pelo turismo, alçando-as à qualidade de algo que "precisa ser conhecido", reflete a importância alcançada pelo discurso sobre as cozinhas regionais. De fato, hoje compreende-se a gastronomia típica não apenas como um manifestação cultural, mas também um atrativo cultural, capaz de materializar para o turista uma série de conteúdos simbólicos. O alimento torna-se assim um objeto semióforo, aquele que segundo Pomian (1984) carrega significados que o ultrapassam.

Com qualidades relacionadas aos significados que lhe são atribuídos, os objetos semióforos são mediadores entre o mundo daqueles que os observam e o mundo que representam. Para De Morais (2004, p. 84) "neste sentido, a culinária típica teria em comum com as exposições museológicas e as coleções o fato de explicitar a cultura humana; são materialidades que representam o invisível".

De Morais (2004), ao analisar a gastronomia mineira do ponto de vista da identidade regional, levanta a questão da monumentalização da comida. Ela se vale da percepção de monumento por Le Goff, que defende:

A palavra latina monumentum remete para a raiz indo-européia men, que exprime uma das funções essenciais do espirito (mens), a memória (memini). O Verbo monere significa "fazer recordar", donde 'avisar', 'iluminar', 'instruir'. O monumentum é um sinal do passado. Atendendo às suas origens filológicas, o monumento é tudo aquilo que pode evocar o passado, perpetuar a recordação (Le Goff, 1984, p. 95). 
Para a autora, "o patrimônio de uma cultura e os monumentos que a compõem dão concretude ao discurso acerca desta cultura, à identidade do grupo. Tais objetos tramam uma urdidura que reapresenta ao grupo seu passado e dá forma concreta a ele". (De Morais, 2004, p. 83). A gastronomia típica, portanto, pode passar por um processo de monumentalização, na medida em que é tomada e reconhecida como um símbolo de um passado que se deseja cultuar, reviver. E o turismo gastronômico, na medida em que valoriza e cria condições para este "culto", constitui-se em uma ferramenta de relevância para este processo. Mais do que a valorização da gastronomia mais tradicional, buscase sua identificação e seu reconhecimento. É nesta perspectiva que cabe introduzir aqui algumas reflexões sobre a patrimonialização alimentar.

\section{Patrimonialização alimentar}

Para Poulain (2004) o fenômeno da patrimonialização alimentar constituise como uma fonte de leitura privilegiada das mutações sociais, pois evidencia uma ressignificação das práticas alimentares:

Ela consiste numa transformação das representações associadas ao espaço social alimentar e coloca os produtos alimentares (quer sejam ou não elaborados), os objetos e as habilidades utilizadas em sua produção, em sua transformação, em sua conservação e em seu consumo, assim como os códigos sociais, 'os modos de cozinha', ou 'os modos de comer e beber' - o que no Ocidente chamamos de 'maneiras à mesa' como objetos culturais portadores de uma parte da história e da identidade de um grupo social (Poulain, 2004, p. 37).

Este movimento - de modo similar a outros movimentos de patrimonialização - tem início diante do temor de desaparecimento eminente de uma edificação ou manifestação. A patrimonialização alimentar, portanto, "emerge num contexto de transformação das práticas alimentares vividas no modo da degradação e mais amplamento no do risco da perda da identidade" (Poulain, 2004, p.38). A mesa se torna, assim, um lugar de resistência identitária.

Poulain (2004) observa que, na França, no final da década de 1960 surgiu um movimento de contraponto ao crescimento contínuo e ao progressismo desenfreado, caracterizando o que Edgard Morin (1996) chama de mentalidade 'neo arcaica', que produz "um duplo retorno dos valores da "natureza" exaltada em oposição ao mundo artificial das ciades e da 'arkhé' rejeitada pela modernidade como rotina e atraso. Esse movimento leva a uma inversão das hierarquias gastronômicas a favor dos pratos rústicos e naturais" (Poulain, 2004, p. 33). Como consequência: 
[...] os cozidos, os pães do campo, a broa de manteiga, surgem na mesa burguesa, as batatas assadas, os diversos assados em fogo à lenha, os legumes "naturais", a procura gourmand de vinhos, azeites, embutidos, produtos coloniais em oposição aos produtos industriais; tudo isso traduz a nova valorização da simplicidade rústica e da qualidade natural que deixam de ser desprezadas em relação à sofisticação e à arte complexa da alta gastronomia (Poulain, 2004, p. 33).

É preciso deixar claro, porém, que para além da ressignificação das práticas alimentares, a patrimonialização da alimentação é um processo que se torna possível diante de uma própria ressignificação da noção de patrimônio. É preciso lembrar que o debate sobre as concepções e estratégias de proteção do patrimônio cultural tem movimentado historiadores, antropólogos, sociólogos e outros estudiosos brasileiros e estrangeiros há várias décadas, tendo em vista que:

[...] el patrimonio cultural no es un hecho dado, una realidad que exista por si misma sino que es una construcción histórica, una concepción y una representación que se crea a través de un proceso en el que se intervienen tanto los distintos intereses de clases y grupos sociales que integran a la nación, como las diferencias históricas y politicas que oponen a los países $^{8}$ (Alvarez, 2002, p.12).

Pensando o exemplo brasileiro, Funari e Pelegrini (2006) fazem uma análise das discussões sobre a concepção de patrimônio e os mecanismos de proteção do patrimônio nacional, evidenciando um processo de construção de varias décadas que culminou no artigo 216 da Constituição da República Federativa do Brasil de 1988, que define como integrantes do Patrimônio Cultural Brasileiro "[...] os bens de natureza material e imaterial, tomados individualmente ou em conjunto, portadores de referência à identidade, à ação, à memória dos diferentes grupos formadores da sociedade brasileira" (BRASIL, 1988). Neste conjunto de bens se incluem:

I- As formas de expressão; II - Os modos de criar, fazer e viver; III -As criações científicas, artísticas e tecnológicas; IV - As obras, objetos, documentos, edificações e demais espaços destinados às manifestações artístico-culturais; V - Os conjuntos urbanos e sítios de valor histórico, paisagístico, artístico, arqueológico, paleontológico, ecológico e científico (Brasil, 1988).

8 "O patrimônio cultural não é fato dado, uma realidade que existe por si mesma, é uma construção histórica, uma concepção e uma representação que é criada através de um processo no qual intervêm tanto os diferentes interesses de classes e grupos sociais que integram a nação, quanto as diferenças históricas e políticas" [tradução livre]. 
Deve-se mencionar que este artigo também estabelece que o poder público, com a colaboração da comunidade, deverá promover e proteger o patrimônio cultural brasileiro por meio de inventários, registros, vigilância, tombamento e desapropriação, além de outras formas de acautelamento e preservação. Neste sentido, tal dispositivo juntamente com outras discussões que se deram nos planos internacional e nacional ${ }^{9}$ - foi fundamental para a criação de um novo instrumento de preservação do país: o Registro de Bens Culturais de Natureza Imaterial, implementado pelo Decreto $\mathrm{n}^{\circ}$. 3.551/2000, publicado em 4 de agosto de 2000 e desde então em vigor (observa-se aqui que tal decreto recupera uma concepção ampla de patrimônio, já ensaiada por Mário de Andrade em suas propostas apresentadas na década de 1930).

Deve-se fazer constar que a ação do Instituto do Patrimônio Histórico e Artístico Nacional, órgão federal responsável pelas questões ligadas ao patrimonio, se coaduna com os preceitos da UNESCO (Organização das Nações Unidas para a Educação, a Ciência e a Cultura), entidade que estabelece as manifestações de Patrimônio Cultural Imaterial como aquelas que incluem as tradições, o folclore, os saberes, as técnicas, as línguas, as festas e diversos outros aspectos e manifestações, transmitidos oral ou gestualmente, recriados coletivamente e modificados ao longo do tempo. Por concepção, o Patrimônio Imaterial é transmitido de geração em geração sendo constantemente recriado pelas comunidades e grupos em função de seu ambiente, de sua interação com a natureza e de sua história, gerando um sentimento de identidade e continuidade que contribui para a promoção do respeito à diversidade cultural e à criatividade humana. Por sua natureza, a gastronomia - ou melhor, os saberes-fazeres a ela relacionados, constituem-se como elementos do patrimônio imaterial.

Como as políticas de reconhecimento patrimonial visam também sua salvaguarda, o Decreto n ${ }^{\circ}$. 3.551/2000 também instituiu que o Registro dos Bens Culturais de Natureza Imaterial sempre terá como referência a continuidade histórica do bem e sua relevância nacional para a memória, a identidade e a formação da sociedade brasileira, e poderá ser feito nos seguintes livros: Livro de Registro dos Saberes (onde serão inscritos conhecimentos e modos de fazer enraizados no cotidiano das comunidades); Livro de

9 Pode-se citar aqui a Recomendação de Paris de 15 de novembro de 1989 (que ressaltava a importância da cultura tradicional e popular e argumentava em favor de sua salvaguarda); a Carta de Fortaleza de 14 de novembro de 1997 (produto do "Seminário Patrimônio Imaterial: Estratégias e Formas de Proteção" promovido pelo IPHAN, documento que argumenta que os bens de natureza imaterial deveriam ser objeto de proteção específica e que os institutos de proteção até então em vigor no âmbito federal não tinham se mostrado adequados à proteção do patrimônio cultural de natureza imaterial. Assim, dentre várias recomendações, a Carta indicava a necessidade de um aprofundamento da reflexão sobre o conceito de bem cultural de natureza imaterial, bem como a criação de um grupo de trabalho no Ministério da Cultura, sob coordenação do IPHAN para propor um instrumento legal que tratasse da criação de um instituto jurídico denominado registro voltado especificamente para os bens de natureza imaterial); e a Carta de Mar Del Plata sobre Patrimônio Intangível de 17 de junho de 1997 (que dentre outras recomendações sugere a ação conjunta dos países do Mercosul no sentido da salvaguarda do patrimônio imaterial, principalmente o concernente às populações indígenas da região) (IPHAN, 2008). 
Registro das Celebrações (inscritos os rituais e festas que marcam a vivência coletiva do trabalho, da religiosidade, do entretenimento e de outras práticas da vida social); Livro de Registro das Formas de Expressão (inscritas manifestações literárias, musicais, plásticas, cênicas e lúdicas) e Livro de Registro dos Lugares (inscritos mercados, feiras, santuários, praças e demais espaços onde se concentram e reproduzem práticas culturais coletivas).

\section{É o Livro de Registro dos Saberes o destino dos saberes-fazeres relacionados} à gastronomia que são cumprem os pré-requisitos para o registro. Atualmente, estão registrados o Ofício das Paneleiras de Goiabeiras ${ }^{10}$, o Ofício das Baianas do Acarajé ${ }^{11}$ e o Modo Artesanal de fazer Queijo de Minas, nas regiões do Serro e das serras da Canastra e do Salitre ${ }^{12}$. Estão em processo de registro o Modo de Fazer tradicional da Cajuína de Piauí, o Ofício de Tacacazeira na Região Norte e a Região doceira de Pelotas - RS.

10 O Ofício das Paneleiras de Goiabeiras foi o primeiro bem cultural inscrito no Livro de Registro dos Saberes, em 20 de dezembro de 2002, e consiste na fabricação artesanal de panelas de barro em Goiabeiras (também conhecido como Goiabeiras Velha), bairro de Vitória, Capital do Espírito Santo. É uma atividade predominantemente feminina e constitui um saber repassado de mãe para filha por gerações sucessivas, constituindo-se também no meio de vida de mais de 120 famílias. As panelas de Goiabeiras são utensílios indispensáveis no preparo de peixes e mariscos, especialmente para preparar e servir a Moqueca Capixaba, uma referência obrigatória da culinária do Espírito Santo e um símbolo da identidade cultural regional. A famosa Torta Capixaba também é tradicionalmente preparada nessas panelas. Dentre as atividades que compõem o Ofício das Paneleiras constam: a extração da argila; preparação das bolas e transporte até o local de trabalho; escolha e/ou limpeza do barro (retirada de gravetos e outras impurezas com o mesmo sendo pisado até ficar mais homogêneo para sofrer a modelagem); coleta da casca de mangue vermelho; confecção da tintura de tanino; modelagem da peça; realização do acabamento da peça (colocação de orelhas, polimento); queima das peças e açoite das peças (aplicação da tinta nas peças com a vassourinha de muxinga). Observa-se que a descrição pormenorizada da modelagem e fabricação das panelas de Goiabeiras consta no Processo $\mathrm{n}^{\circ}$. 01450.000672/2002-50 (IPHAN, 2002).

11 Segundo relato do Processo $\mathrm{n}^{\circ}$. 01450.008675/2004-01, o pedido de registro do Ofício das Baianas do Acarajé foi inscrito no Livro dos Saberes como Patrimônio Cultural Brasileiro em 10 de dezembro de 2004. De acordo com o Livro de Registro dos Saberes, o Ofício das Baianas de Acarajé, em Salvador, Bahia, consiste em uma prática tradicional de produção e venda em tabuleiro das chamadas comidas de baiana ou comidas de azeite, em que se destaca o acarajé, um bolinho de feijão fradinho, frito no azeite de dendê. O preparo do acarajé foi levado para a região pelas escravas negras no período colonial e tem sido reproduzido no Brasil desde então, tendo na transmissão oral sua principal forma de transmissão de receitas. De origem sagrada, associada ao culto de divindades do candomblé, esta comida popularizou-se e passou a marcar toda a sociedade baiana como um valor alimentar integrado à culinária regional. Neste sentido, são considerados elementos essenciais do Ofício das Baianas do Acarajé os rituais envolvidos na produção do acarajé, na arrumação do tabuleiro e na preparação do lugar onde as baianas se instalam; os modos de fazer as comidas de baiana; o uso do tabuleiro para venda das comidas; a comercialização informal em logradouros, feiras e festas de largo e o uso da indumentária própria das baianas (IPHAN, 2004).

12 O Modo Artesanal de fazer Queijo de Minas, nas regiões do Serro e das serras da Canastra e do Salitre foi inscrito no Livro de Registro dos Saberes, em 13 de junho de 2008, mediante o entendimento de que o modo de fazer o queijo sintetiza um conjunto de experiências, símbolos e significados que definem a identidade do mineiro. Trata-se, portanto, de um conhecimento tradicional e um traço marcante da identidade cultural dessas regiões, sendo que cada uma forjou um modo de fazer próprio, expresso na forma de manipulação do leite, dos coalhos e das massas, na prensagem, no tempo de maturação (cura), conferindo a cada queijo aparência e sabores específicos. Observa-se que a descrição pormenorizada do modo de fazer do Queijo de Minas consta no Processo $n^{\circ}$. 01450.012192/2006-65 (IPHAN, 2008). 
A ação do IPHAN no registro e salvaguarda de tais bens imateriais merece nota, pois em um contexto em que se verifica o avanço da industrialização alimentar e a dissolução de muitas tradições da mesa em nome da rapidez e praticidade, o registro dos saberes alimentares visa não apenas salvaguardar técnicas e receitas, mas principalmente reconhecer tais práticas como pertencentes a um contexto cultural maior e como uma forma de expressão legítima do grupo social que a desenvolve.

Ainda, é interesante observar, porém, que no Brasil não é comum o uso de denominações como DOP (Denominação de Origem Protegida) e DOC (Denominação de Origem Controlada), que são amplamente utilizados em países europeus para referendar produtos como vinhos, queijos, pães e outras iguarias, e que terminam por funcionar como verdadeiros selos de qualidade. Percebe-se que no Brasil a questão da patrimonialização alimentar caminha a passos muito lentos, se comparada às realidades de países como França, Itália e Espanha, que consideram suas gastronomias não apenas marcos identitários (monumentos), mas também importantes atrativos turísticos. 


\section{CONSIDERAÇÕES FINAIS}

A questão da globalização e a padronização das manifestações culturais é um assunto que vem sendo muito debatido no âmbito das ciências humanas, seja na sociologia, na antropologia ou na filosofia. Mesmo não sendo o objeto central, a atividade turística muitas vezes surge como exemplo de catalizador das experiências da alteridade, bem como como um vetor trocas culturais nem sempre tidas como benéficas. A própria discussão da sustentabilidade do turismo, em seus termos socioeconômicos e culturais, preocupa-se com esta questão, buscando maneiras de conter homogeneizações e descaracterizações. A "globalização do gosto alimentar", por sua vez, está presente no cotidiano dos que vivem centros urbanos no mundo inteiro. Ingredientes, técnicas e maneiras de serviço à mesa são hoje disseminados e assimilados mundo a fora, provocando uma desterritorialização alimentar nunca antes conhecida. A extinção eminente de práticas culinárias tradicionais - ou pelo menos o receio de que tal extinção efetivamente aconteça - tem gerado movimentos de valorização das mesmas, aspecto evidente diante do crescimento dos restaurantes de comida típica nos grandes centros urbanos; da inclusão de ingredientes e receitas tradicionais por parte dos grandes chefs de cozinha de ingredientes e receitas tradicionais no cardápio de restaurantes renomados - mesmo que revisitados com técnicas internacionais - ; e na proliferação do uso de adjetivos como "tradicional", "típico" e "original" em diversos itens da indústria alimentar (a menção a estes adjetivos busca separar alguns produtos dos outros, criando uma aura de credibilidade alimentar que muitas vezes não está lá).

É aqui que cabe ressaltar, nesta breve reflexão, o papel do turismo nesse processo de valorização e de compreensão da gastronomia tradicional como uma fonte de experiência cultural. Isso porque, se por um lado a patrimonialização alimentar institucional promovida pelo IPHAN ainda inclui poucas manifestações, a "patrimonialização turística", na medida em que reconhece, valoriza e divulga sublinhando sua tipicidade e tradicionalidade, colabora para manter viva uma série de manifestações gastronômicas. Logicamente que esta apropriação turística do patrimônio gastronômico pode gerar, para além dos beneficios, uma série de distorções. Contudo, por sua complexidade, este é um aspecto que demanda todo um conjunto de novas reflexões, que escapam do escopo deste artigo.

Encerrando, debe-se mencionar que a temática da patrimonialização alimentar ainda é tratada por poucos autores, embora a discussão tenha se ampliado nos últimos anos. No caso brasileiro, para além da discussão das ações e alternativas de patrimonialização, cabe ainda estudos que analisem os resultados que vem sendo alcançados pelos programas de salvaguarda voltados para os saberes-fazeres gastronômicos já registrados. As possibilidades de pesquisa sobre a tema, assim como sua complexidade e especificiddes, são muitas. 


\section{BIBLIOGRAFIA}

Alvarez, M. (2002). La cocina como patrimônio (in)tangible. In: MARONESE, I. (org). Primeras jornadas de patrimonio gastronômico. CPPHC-CABA: Buenos Aires, p.11.

Brasil Contreras, J; Gracia, M. (2011). Alimentação, cultura e sociedade. Rio de Janeiro: Fiocruz.

Csergo, J. (1998). A emergência das cozinhas regionais. In: FLANDRIN, J. L; MONTANARI, M. História da Alimentação. 4. ed. São Paulo: Liberdade, p.806-824.

De Morais, L. P. (2004). Culinária típica e identidade regional: a expressão dos processos de construção, reprodução e reinvenção da mineiridade em livros e restaurantes de comida típica. Belo Horizonte, Dissertação (Mestrado em História), Universidade Federal de Minas Gerais.

Fischler, C. (1979). Gastro-nomie et gastro-anomie: sagesse du corps et crise bioculturelle de l'alimentation moderne. In: Communications, 31, p.189,210.

Funari, P. P.; Pelegrini, S. C. A. (2006). Patrimônio Histórico e cultural. Rio de Janeiro: Jorge Zahar.

Garine, I. De. (1987). Alimentação, culturas e sociedades. In: O Correio. Rio de Janeiro, v. 15, n. 7 , p. $4-7$, jul.

Hughes, G. (1995). Food, tourism and Scottish heritage. In: Leslie, D. (org). Tourism and leisure - cultura, heritage and participation. Brighton:LSA.

IPHAN. (2002). Processo n.01450.000672/2002-50 - Processo de Registro de Patrimônio Imaterial Ofício das Paneleiras de Goiabeiras, ES. Rio de Janeiro, 15 jan.

. (2004). Processo n.01450.008675/2004-01 - Processo de Registro de Patrimônio Imaterial Ofício das Baianas de Acarajé em Salvador, BA. Salvador, 01 dez.

. (2008). Processo no. 01450.012192/2006-65 - Processo de Registro de Patrimônio Imaterial Modo Artesanal de fazer Queijo de Minas, nas regiões do Serro e das serras da Canastra e do Salitre, MG. Brasília, 13 jun.

Le Goff, J. (1984). Documento/monumento. In: Memória - História. Enciclopedia Einaudi. Lisboa: Casa da Moeda, Imprensa Nacional, v.1.

Morin, E. (1996). Rationalité et rationalisacion. In: Fischler, C. Pensée magique et alimentation aujourd'hui, Cahiers de l'OCHA, n.5, p.109-110.

Pomian, K. (1984) .In: Memória - História. Enciclopedia Einaudi. Lisboa: Casa da Moeda, Imprensa Nacional, v.1.

Poulain, J. P. (2004). Sociologias da alimentação - os comedores e o espaço social alimentar. Florianópolis: UFSC.

Schlüter, R. (2006). Turismo y patrimonio gastronômico - una perspectiva. Buenos Aires:CIET. 
Ortiz, R. (1996). Mundialização e cultura. São Paulo: Brasiliense.

Recibido 18/01/2013

Aceptado 25/04/2013

Arbitrado anónimamente 